\title{
Posterior Predictive of Bayesian Vector Autoregressive (BVAR) and Adjusting Transformation on the Spatio Temporal Disaggregation Method: Predict Hourly rainfall data at the outsampled Locations
}

\author{
Suci Astutik \\ Brawijaya University, Indonesia \\ suci_sp@ub.ac.id \\ Umu Sa'adah \\ Brawijaya University, Indonesia \\ u.saadah@ub.ac.id \\ Supriatna Adhisuwignjo \\ Brawijaya University, Indonesia \\ supriatna_s@yahoo.com \\ Rauzan Sumara \\ Brawijaya University, Indonesia \\ rauzan.sumara@yahoo.com
}

\begin{abstract}
This research is a development from previous research that has studied the method of spatio temporal disaggregation with State space and adjusting procedures for predicting hourly rainfall based on daily rainfall (Astutik et al, 2013). However, this study is limited to predicting hourly rainfall in some sampled locations in the future. Astutik et al $(2017,2018)$ have modeled hourly and daily rainfall using posterior predictive bayesian VAR at the Sampean watershed of Bondowoso. This study aims to predict hourly rainfall data based on daily rainfall data in the future at the outsampled locations using posterior predictive bayesian VAR and adjusting procedures in the method of spatio temporal disaggregation.
\end{abstract}

Keywords: Posterior predictive Bayesian VAR; Adjusting procedure; Disaggregation; Spatio temporal.

\section{Introduction}

The method of spatio temporal disaggregation is a method for prediction or generating low scale (hourly) data from high-scale (daily) data involving time and location information. There are two stages in the disaggregation method, namely (1) modeling of low time scale rainfall data (eg hourly data) and high time scales (eg daily data) and (2) maintaining the consistency of low time scale rainfall data with high time scales.

Koutsoyiannis et al (2003); Bojilova, 2004; Segond et al., 2006, 2007 have developed a spatio temporal disaggregation method to generate synthetic (prediction) data involving two resolutions / time scales (high and low time scales) which require that low scale data synthetic series must be consistent with high scale data observation series involving location information (space) and time. Koutsoyiannis et al. (2003) have developed spatiotemporal disaggregation by combining Simple Multivariate Autoregressive time series models (MAR (1)) and Bartlett Lewis rain models and coupling procedures. Coupling method is used to guarantee the consistency of low scale synthetic data (hourly) with high 
scale observation data (daily). Makhnin (2009); Sigrist et al (2011) have developed the Bayesian approach with the Gibbs sampler algorithm for generation of rain events and daily rainfall intensity based on a normal truncated and power transformed (TPT) distribution through a state-space model. However, these two approaches have difficulty in creating the results of synthetic rainfall (generation data) on a location grid (regionalization). In addition, this model cannot produce low scale time data based on high time scales.

Astutik et al. (2013) combined the Bayesian state space model and Coupling method to disaggregate high scale into low scale rainfall data at the Sampean watershed of Bondowoso. This combination of models is able to produce low scale rainfall data that can illustrate well the phenomenon of low scale rainfall data at the Sampean watershed of Bondowoso. However, this model is only capable of producing low scale data in the sampled location. This model has not been able to interpolate low scale rainfall from high scale rainfall at the outsampled locations.

Congdon (2006), in Bayesian statistics, the distribution of posterior predictive is the distribution of unconditional (predictive) observations on sampled data (observation). Unlike the classical method such as maximum likelihood, the results of parameter estimation resulting in a prediction distribution are not a point estimator. This is one of the advantages of Bayesian estimation.

Therefore the purpose of this study was to develop a posterior predictive model of Bayesian Vector Autoregressive (VAR) on the method of spatio temporal disaggregation to predict or generate low time scale data at the outsampled locations. By using this model, the results of low time scale data predictions can be used as input for the rain model simulation of spatially distributed flows in the watershed. Then it can be implemented in the flood simulation model.

\section{Methodology}

\section{Data source}

This study involved hourly and daily rainfall data in the Sampean Watershed in the 2016 and 2007 periods at the Sentral, Maesan and Tlogo rain stations. Hourly and daily rainfall data at Sentral and Maesan are used as training data. While the hourly and daily rainfall data in Tlogo are testing data. In this research, there are three prediction cases: (1) Predict or generate hourly data for insampled locations, (2) Predict or generate hourly data for outsampled locations, and (3) Predict or Generate hourly data in the future for insampled and outsampled locations.

\section{Stages of Research}

Stage 1. Formalize hourly and daily rainfall models using Bayesian VAR model. Algorithm of posterior predictive Bayesian VAR model for spatio temporal disaggregation, which is detailed as follows:

1. Define Vector Autoregressive (VAR (p), 


$$
\begin{array}{r}
\boldsymbol{Z}_{t}^{\prime}=\boldsymbol{\Theta}^{\prime}+\sum_{i=1}^{p} \boldsymbol{Z}_{t-i}^{\prime} \boldsymbol{\Phi}_{i}^{\prime}+\boldsymbol{\varepsilon}^{\prime}{ }_{t} \\
\boldsymbol{Y}=\mathbf{X} \boldsymbol{\Phi}+\boldsymbol{\varepsilon}
\end{array}
$$

where,

$$
\boldsymbol{Y}=\left(\begin{array}{c}
\boldsymbol{Z}_{p+1}^{\prime} \\
\vdots \\
\boldsymbol{Z}^{\prime}{ }_{T}
\end{array}\right), \boldsymbol{X}=\left(\begin{array}{cccc}
\mathbf{1} & \boldsymbol{Z}^{\prime}{ }_{p} & \cdots & \boldsymbol{Z}^{\prime}{ }_{1} \\
\vdots & \vdots & \cdots & \vdots \\
\mathbf{1} & \boldsymbol{Z}^{\prime}{ }_{T-1} & \ddots & \boldsymbol{Z}^{\prime}{ }_{T-p}
\end{array}\right), \boldsymbol{\Phi}=\left(\begin{array}{c}
\boldsymbol{\Theta}^{\prime} \\
\boldsymbol{\Phi}^{\prime}{ }_{1} \\
\vdots \\
\boldsymbol{\Phi}^{\prime}{ }_{p}
\end{array}\right), \text { dan } \boldsymbol{\varepsilon}=\left(\begin{array}{c}
\boldsymbol{\varepsilon}^{\prime}{ }_{P+1} \\
\vdots \\
\boldsymbol{\varepsilon}^{\prime}{ }_{T}
\end{array}\right)
$$

$\boldsymbol{Y}$ and $\boldsymbol{\varepsilon}$ are $(\boldsymbol{T}-\boldsymbol{p}) \times \boldsymbol{m}$ matrices, $\boldsymbol{X}$ is $(\boldsymbol{T}-\boldsymbol{p}) \times(\mathbf{1}+\boldsymbol{m} \boldsymbol{p})$ matrix of observations, and $\boldsymbol{\Phi}$ is $(\mathbf{1}+\boldsymbol{m} \boldsymbol{p}) \times \boldsymbol{m}$ matrix of unknown parameters. Defined $\boldsymbol{N}=\boldsymbol{T}-\boldsymbol{p}$, then likelihood function can be written as

$$
L(\mathbf{Y} \mid \boldsymbol{\Phi}, \boldsymbol{\Sigma})=(2 \pi)^{-\frac{N m}{2}}|\boldsymbol{\Sigma}|^{-\frac{N}{2}} \exp \left\{-\frac{1}{2} \operatorname{tr}\left[\boldsymbol{\Sigma}^{-1}(\boldsymbol{Y}-\mathbf{X} \boldsymbol{\Phi})^{\prime}(\boldsymbol{Y}-\mathbf{X} \boldsymbol{\Phi})\right]\right\}
$$

and MLEs of $\boldsymbol{\Phi}$ and $\boldsymbol{\Sigma}$ are

$$
\widehat{\boldsymbol{\Phi}}=\left(\mathbf{X}^{\prime} \mathbf{X}\right)^{-1} \mathbf{X}^{\prime} \boldsymbol{Y} \quad \text { and } \quad \widehat{\boldsymbol{\Sigma}}=\frac{\boldsymbol{S}(p)}{N}=\frac{(\boldsymbol{Y}-\mathbf{X} \boldsymbol{\Phi})^{\prime}(\boldsymbol{Y}-\mathbf{X} \boldsymbol{\Phi})}{T-p}
$$

2. Define prior distribution of $\boldsymbol{\Phi}$ and $\boldsymbol{\Sigma}$,

$$
\begin{aligned}
\operatorname{vec}(\boldsymbol{\Phi}) & \sim \mathrm{N}\left(\operatorname{vec}\left(\boldsymbol{\Phi}_{0}\right), \boldsymbol{V}_{0}\right) \\
\boldsymbol{\Sigma}^{-1} & \sim \operatorname{Wishart}\left(\mathbf{S}_{0}^{-1}, n_{0}\right)
\end{aligned}
$$

Where $\Phi_{0}, V_{0}, S_{0}$, and $v_{0}$ are hyperparameter. Initialization of hyperparamter use non informative prior such as $\boldsymbol{S}_{\mathbf{0}}, \boldsymbol{V}_{\mathbf{0}}, \boldsymbol{\Phi}_{\mathbf{0}}$, and $\boldsymbol{n}_{\mathbf{0}}$ near to zero.

The join posterior is obtained :

$$
\begin{gathered}
f(\boldsymbol{\theta}) \propto f(\operatorname{vec}(\boldsymbol{\Phi})) f\left(\boldsymbol{\Sigma}^{-1}\right) \\
\propto|\boldsymbol{\Sigma}|^{-\frac{N}{2}} \exp \left\{-\frac{1}{2} \operatorname{tr}\left[\boldsymbol{\Sigma}^{-\mathbf{1}}(\boldsymbol{Y}-\mathbf{X} \boldsymbol{\Phi})^{\prime}(\boldsymbol{Y}-\mathbf{X} \boldsymbol{\Phi})\right]\right\} \\
\times\left|\boldsymbol{V}_{0}\right|^{-\frac{1}{2}}\left|\mathbf{S}_{0}\right|^{\frac{n_{0}}{2}}|\boldsymbol{\Sigma}|^{-\frac{n_{0}-m-1}{2}} \exp \left\{-\frac{1}{2}\left[\operatorname{tr}\left(\boldsymbol{\Sigma}^{-1} \mathbf{S}_{0}\right)\right.\right. \\
\left.\left.+\operatorname{vec}\left(\boldsymbol{\Phi}-\mathbf{\Phi}_{0}\right)^{\prime} \boldsymbol{V}_{0}^{-1} \operatorname{vec}\left(\boldsymbol{\Phi}-\mathbf{\Phi}_{0}\right)\right]\right\} \\
|\boldsymbol{\Sigma}|^{-\frac{N+n_{0}-m-1}{2}}\left|\boldsymbol{V}_{0}\right|^{-\frac{1}{2}} \exp \left\{-\frac{1}{2} \operatorname{tr}\left[\boldsymbol{\Sigma}^{-1}\left((\boldsymbol{Y}-\mathbf{X} \boldsymbol{\Phi})^{\prime}(\boldsymbol{Y}-\mathbf{X} \boldsymbol{\Phi})+\mathbf{S}_{0}\right)\right]\right\} \times \\
\exp \left\{-\frac{1}{2}\left[\operatorname{vec}\left(\boldsymbol{\Phi}-\propto\left|\mathbf{S}_{0}\right|^{\frac{n_{0}}{2}} \boldsymbol{\Phi}_{0}\right)^{\prime} \boldsymbol{V}_{0}^{-1} \operatorname{vec}\left(\boldsymbol{\Phi}-\mathbf{\Phi}_{0}\right)\right]\right\}
\end{gathered}
$$

3. Use Markov Chain Monte Carlo (MCMC) methods to estimate the parameter of $\boldsymbol{\Sigma}$ and $\boldsymbol{\Phi}$. The conditional posterior distribution is used to process in Gibbs Sampler 
algorithm.

4. Obtain other measures of interest might be posterior such as $2.5 \%$ and $97.5 \%$ credible interval.

5. Calculate Monte Carlo Error (MC Error).

6. Diagnostic model using MAE

$$
M A E=\frac{\sum_{i=1}^{n}\left|Y_{i}-\hat{Y}_{i}\right|}{n}
$$

7. Generate spatio-temporal low scale data at some locations (insampled and outsampled) using posterior predictive bayesian VAR as follows:

$p(\tilde{x} \mid \mathbf{X}, \alpha)=\int_{\theta} p(\tilde{x} \mid \boldsymbol{\theta}, \mathbf{X}, \alpha) p(\theta \mid \mathbf{X}, \alpha) d \theta$

Where $\theta$ is parameter and $\alpha$ is hyperparameter

Stage 2 Maintain consistency of hourly rainfall data with daily rainfall data by using adjusting transformations. The combination of the Bayesian VAR model and adjusting transformations is obtained spatio temporal disaggregation as follows:

$$
\hat{Y}_{l}^{s}=\frac{Z_{t}^{s}}{\tilde{Z}_{t}^{s}} \tilde{Y}_{l}^{s}, \quad l=(t-1) k+1 ; \quad t=1, \ldots, T ; \quad s=1, \ldots, n ; \quad k=24,
$$

Where $\hat{Y}_{l}^{s}$ is the generation low scale data after adjusting procedure on t period, l subperiod, at s location, $Z_{t}^{s}$ is the observation high scale data on t period at s location, $\tilde{Y}_{l}^{s}$ is the generation low scale data before adjusting procedure on $t$ period, $l$ subperiod, at $s$ location obtained by using Bayesian $V A R, \tilde{Z}_{t}^{s}$ is the generation high scale data before adjusting procedure on $t$ period at $s$ location, which is total of all $\tilde{Y}_{l}^{s}$ or $\sum_{l=(t-1) k+1}^{t k} \tilde{Y}_{l}^{s}=\tilde{Z}_{t}^{s}$. Adjusting procedure carried out such that $\sum_{l=(t-1) k+1}^{k} \hat{Y}_{l}^{s}=Z_{t}^{s}$.

\section{Result and Discussion}

Low time scale (hourly) generation data is carried out through the BVAR (5) model which has been estimated in the previous stage (Astutik et al, 2018). As many as 1488 generation data are considered as low-scale observation data in two locations (consider to the covariance between locations), then every 24 generated data is summed to obtain high-time data, so that 62 high-time data are obtained. This generation data assume that residual vektor $\left[\begin{array}{l}\varepsilon_{1, t} \\ \varepsilon_{2, t}\end{array}\right]$ have normal multivariate distribution with mean vector $\boldsymbol{\mu}=\left[\begin{array}{l}0 \\ 0\end{array}\right]$ and varians covarians matrix $\Sigma=\left[\begin{array}{ll}1.0000 & 0.0268 \\ 0.0268 & 1.0000\end{array}\right]$. The BVAR model used is as follows:

$$
\begin{aligned}
{\left[\begin{array}{l}
Y_{1, t} \\
Y_{2, t}
\end{array}\right] } & =\left[\begin{array}{ll}
0.3286 & 0.0392 \\
0.0294 & 0.1050
\end{array}\right]\left[\begin{array}{l}
Y_{1, t-1} \\
Y_{2, t-1}
\end{array}\right]+\left[\begin{array}{ll}
0.0652 & 0.1012 \\
0.0030 & 0.0172
\end{array}\right]\left[\begin{array}{l}
Y_{1, t-2} \\
Y_{2, t-2}
\end{array}\right]+\left[\begin{array}{cc}
0.0845 & -0.0374 \\
0,0716 & 0.0530
\end{array}\right]\left[\begin{array}{l}
Y_{1, t-3} \\
Y_{2, t-3}
\end{array}\right] \\
& =+\left[\begin{array}{ll}
0.0174 & -0.0136 \\
0.0180 & -0.0055
\end{array}\right]\left[\begin{array}{l}
Y_{1, t-4} \\
Y_{2, t-4}
\end{array}\right]+\left[\begin{array}{cc}
-0.0409 & 0.0400 \\
0.0624 & 0.1637
\end{array}\right]\left[\begin{array}{l}
Y_{1, t-5} \\
Y_{2, t-5}
\end{array}\right]+\left[\begin{array}{l}
\varepsilon_{1, t} \\
\varepsilon_{2, t}
\end{array}\right]
\end{aligned}
$$

The First Case, Predict or generate hourly data for insampled locations (Sentral and Maesan raingage). 
The comparison of hourly data (low time scale) between the posterior predictive BVAR and adjusting procedure with observation data at the insample locations (Sentral and Maesan raingage) can be seen in Figure 1. Meanwhile the daily rainfall prediction data (a total of 24 hourly prediction data) with daily observation data at the insample location is presented in the Figure 2.

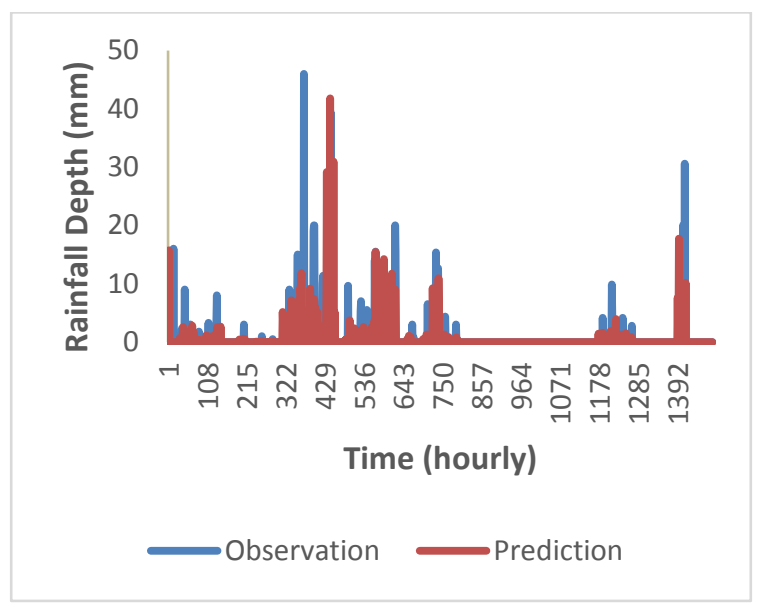

(a) Sentral

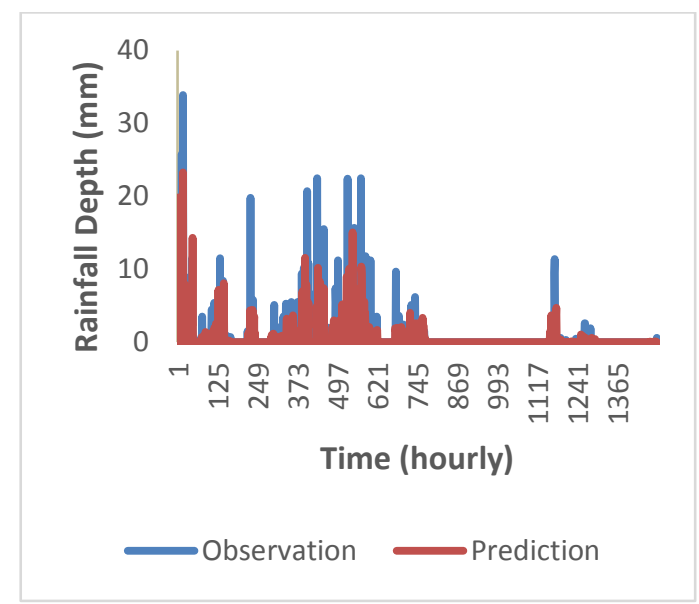

(b) Maesan

Figure 1. Comparison of low time scale data (hourly) between Observation and Prediction data at the insampled locations (a) Sentral raingage and (b) Maesan raingage

Based on Figure 1 shows that there are no differences in patterns between hourly predictive and observations rainfall data at the insample location (Sentral and Maesan raingages). This is also supported by the $\mathrm{p}$ value of the $\mathrm{t}$ test result of 1 . $(>\alpha=5 \%)$.

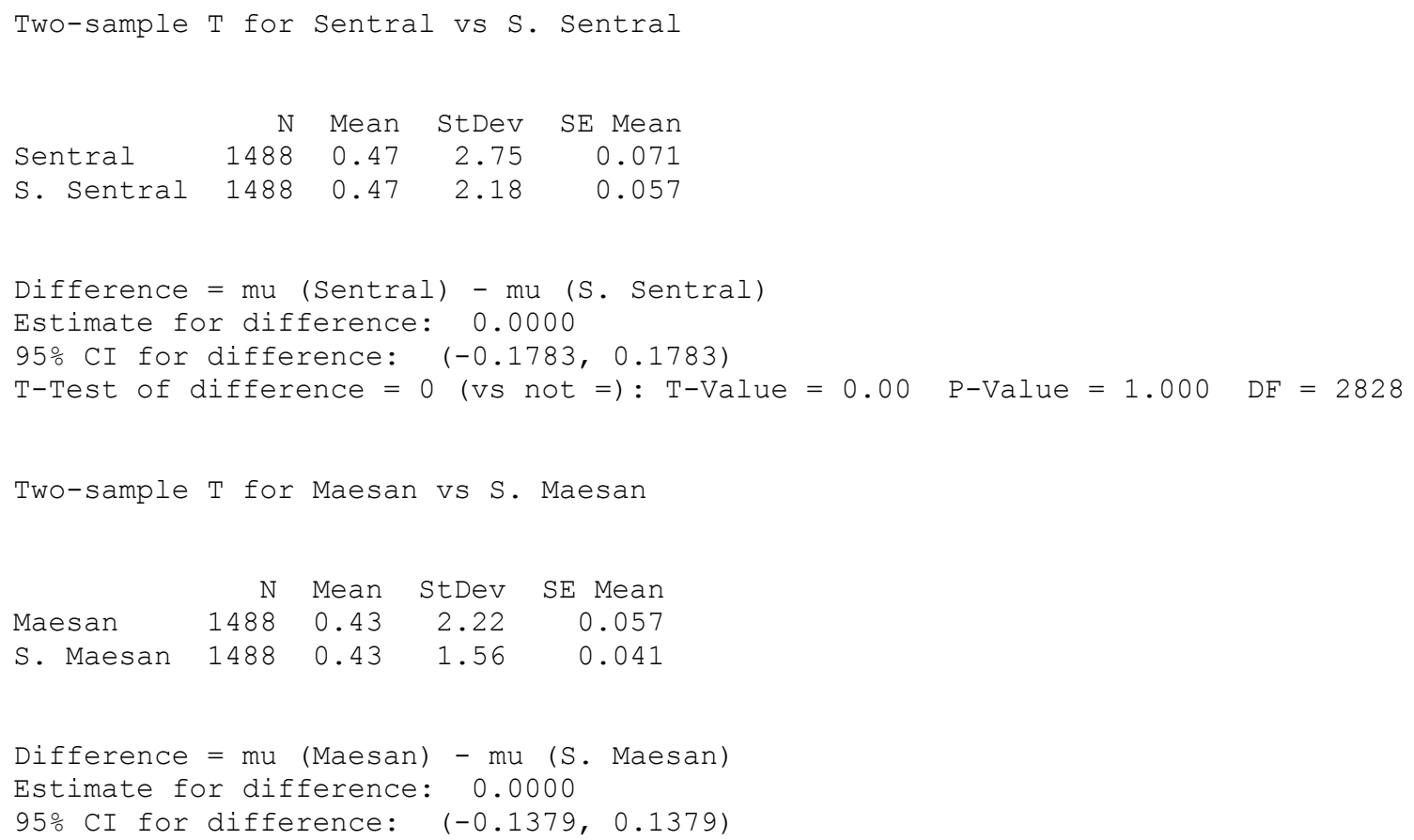


$\mathrm{T}$-Test of difference $=0$ (vs not $=$ ) : T-Value $=0.00 \quad$ P-Value $=1.000 \quad \mathrm{DF}=2671$

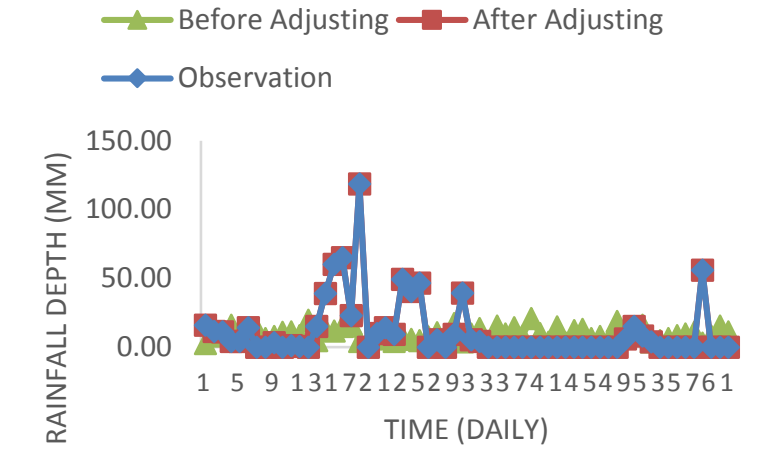

(a) Sentral

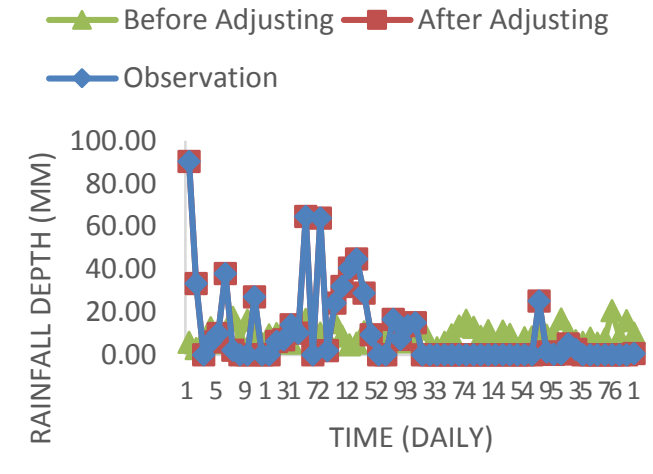

(b) Maesan

Figure 2. Comparison of high time scale data (daily) between Observation and Prediction data (Before and After adjusting) at raingages (a) Sentral and (b) Maesan

Based on Figure 2 it is seen that there is no difference in plot between daily rainfall data between posterior predictive BVAR with adjusting procedure and observation compared without adjusting procedure. Figure 3 shows relationship between daily observastion and posterior predictive BVAR with and without adjusting procedure.

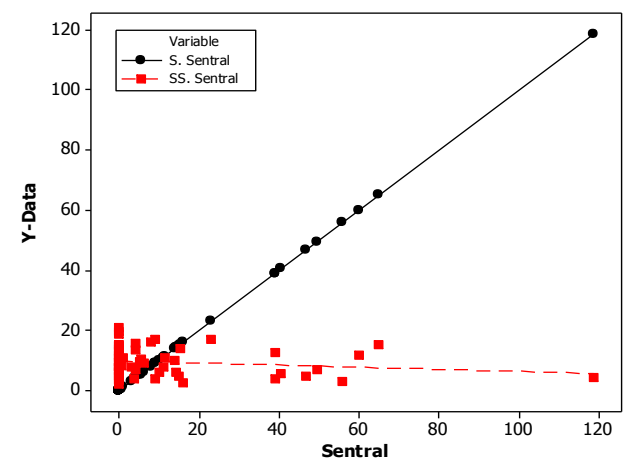

(a) Sentral

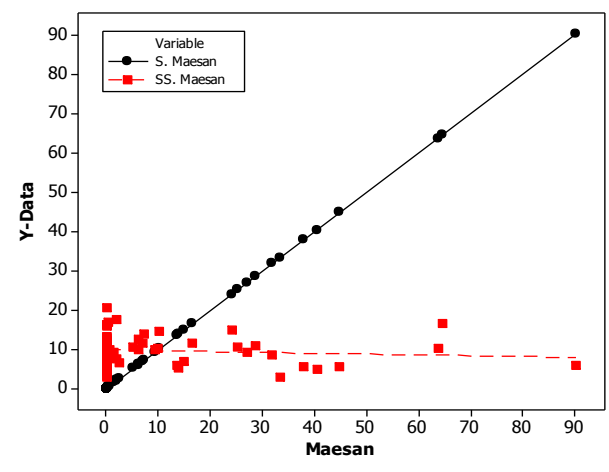

(b) Maesan

Figure 3. Plot of high time scale data (daily) between Observation vs Posterior Prediction BVAR with adjusting and without adjusting at raingages (a) Sentral and (b) Maesan

Figure 3 shows the plot line between the daily data between the posterior predictive BVAR and adjusting procedure and daily observations that form an angle of $45^{\circ}\left(\mathrm{R}^{2}=\right.$ $100 \%)$. This means that the daily data of the posterior predictive predictions of BVAR with adjusting procedure are similar to the daily observational data. Conversely the plot line between the daily data between the posterior predictive BVAR without adjusting procedure and daily observation does not show a linear relationship $\left(\mathrm{R}^{2}=2.7 \%\right)$. This means that the spatio temporal disaggregation method using posterior predictive BVAR and adjusting procedure is able to produce hourly rainfall data based on daily observation data. 
To find out the goodness of the model, it is necessary to see the accuracy of the model with MAE (mean Absolute Error) as shown on Table 1.

Table 1. Comparison of model accuracy at the in sampled locations

\begin{tabular}{|c|c|}
\hline Raingage & MAE \\
\hline Sentral & 0.0002 \\
\hline Maesan & 0.0066 \\
\hline
\end{tabular}

Based on Table 1 it can be seen that the MAE value of the spatio temporal disaggregation method using posterior predictive BVAR and adjusting procedure at the insampled locations (Sentral and Maesan) is very small. This means that the spatio temporal disaggregation method using posterior predictive BVAR and adjusting procedure can produce hourly rainfall data which is no different from the hourly observation rainfall data. So as total of 24 hourly prediction rainfall data is same as daily observation data.

The Second Case. Predict or generate hourly data for outsampled locations.

In this case, low time scale data on outsampled locations (Tlogo raingage) will be predicted or generated based on hourly and daily rainfall observations data at the insampled locations (Sentral and Maesan raingage) using the spatio temporal disaggregation method. The method which is developed in this study is a combination of posterior predictive BVAR and adjusting procedure. Comparison of hourly rainfall data of posterior predictive BVAR and adjusting procedure with observation data can be seen in the Figure 4. Meanwhile the daily rainfall prediction data (a total of 24 hourly prediction data) with daily observation data at the outsampled location is presented in the Figure 5.

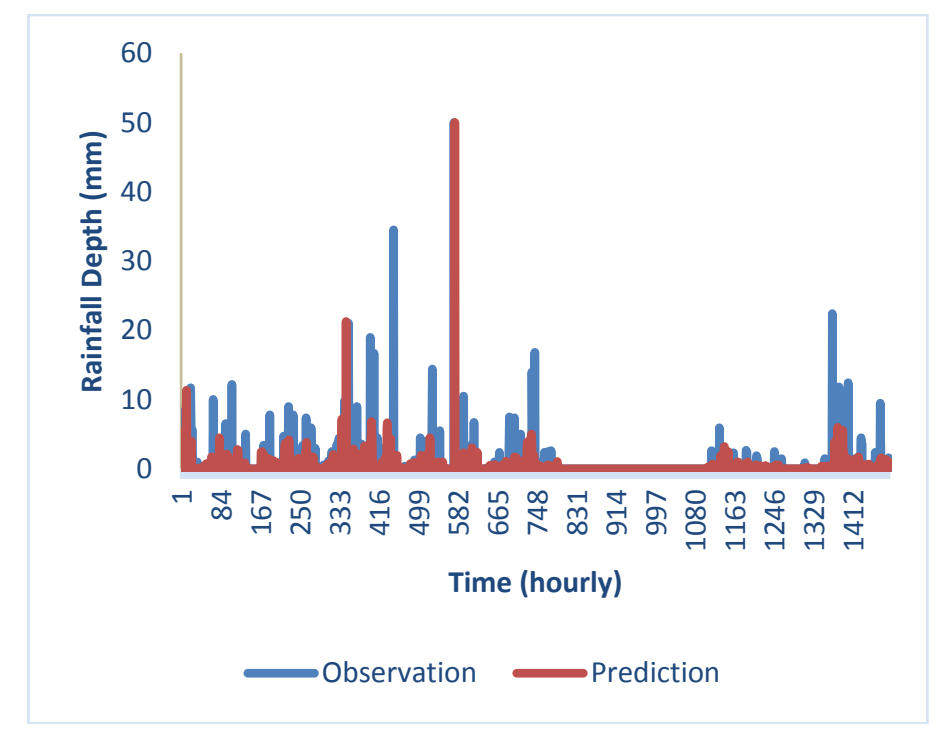

Figure 4. Comparison of low time scale data (hourly) between Observation and Prediction data at the Tlogo raingage (the outsampled location)

Based on Figure 4 shows that there are no differences in patterns between hourly 
predictive and observations rainfall data at the outsampled location (Tlogo raingage). This is also supported by the $\mathrm{p}$ value of the t test result of $1 .(>\alpha=5 \%)$.

Two-sample T for Tlogo vs S. Tlogo

$\begin{array}{lrrrr} & \text { N } & \text { Mean } & \text { StDev } & \text { SE Mean } \\ \text { Tlogo } & 1488 & 0.38 & 2.32 & 0.060 \\ \text { S. Tlogo } & 1488 & 0.38 & 1.65 & 0.043\end{array}$
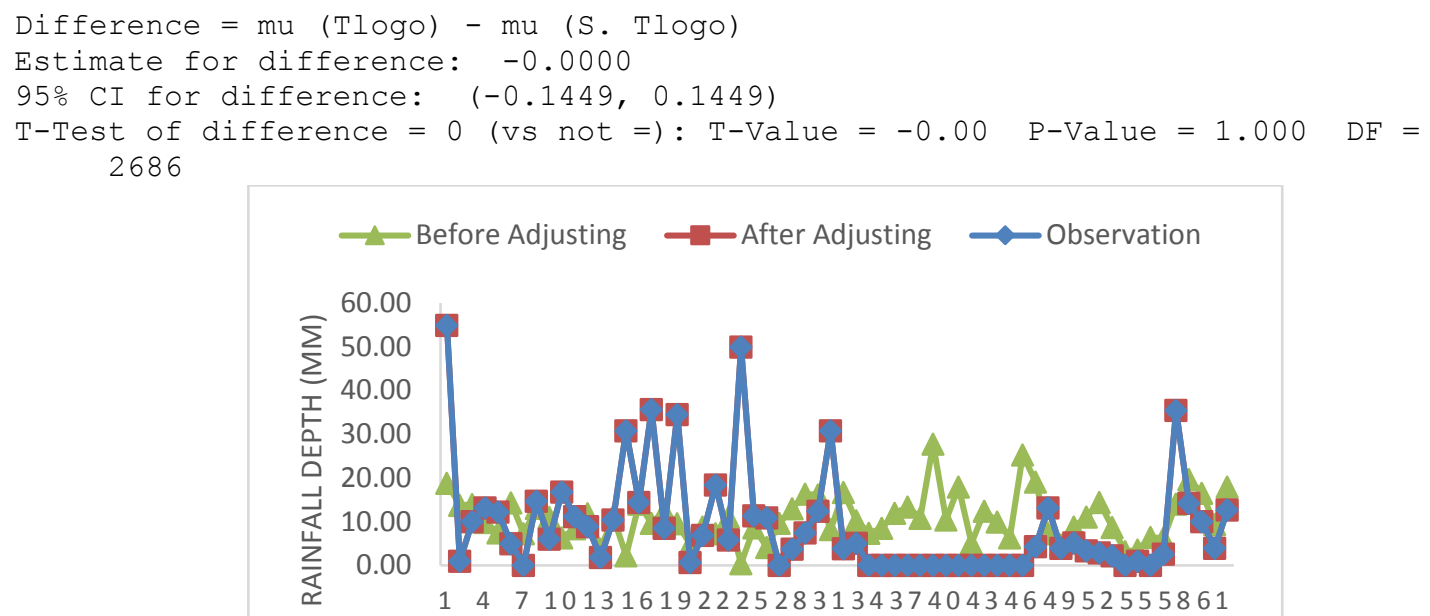

TIME (DAILY)

Figure 5. Comparison of high time scale data (daily) between Observation and Prediction data at the Tlogo raingage (the outsampled location)

Based on Figure 5 it is seen that there is no difference in plot between daily rainfall data between posterior predictive BVAR with adjusting procedure and observation compared without adjusting procedure. Figure 6 shows relationship between daily observation and posterior predictive BVAR with and without adjusting procedure at the outsampled location (Tlogo raingage).

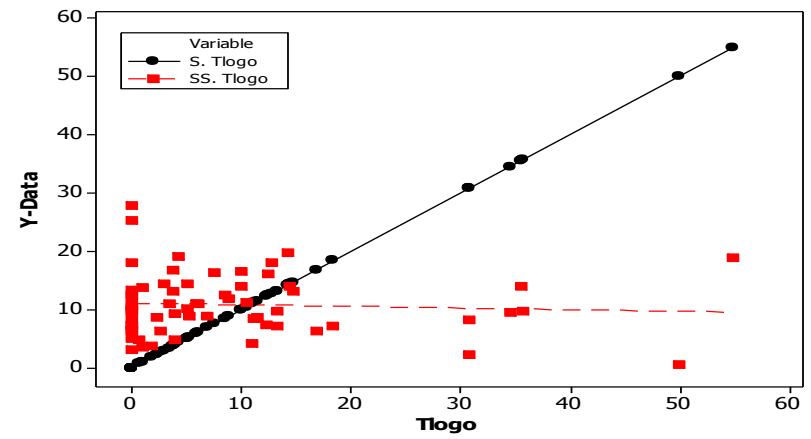

Figure 6. Plot of high time scale data (daily) between Observation vs Posterior Prediction BVAR with adjusting and without adjusting at the Tlogo raingage

Figure 6 shows the plot line between the daily data between the posterior predictive BVAR and adjusting procedure and daily observations that form an angle of $45^{\circ}\left(\mathrm{R}^{2}=\right.$ $100 \%)$. This means that the daily data of the posterior predictive predictions of BVAR 
with adjusting procedure are similar to the daily observational data. Conversely the plot line between the daily data between the posterior predictive BVAR without adjusting procedure and daily observation does not show a linear relationship $\left(\mathrm{R}^{2}=0.4 \%\right)$. This means that the spatio temporal disaggregation method using posterior predictive BVAR and adjusting procedure is able to produce hourly rainfall data based on daily observation data at the outsampled location (Tlogo raingage). MAE value of posterior predictive BVAR and adjusting procedure at the outsampled location (Tlogo raingage) is 0.0055 . It mean that the MAE value of the spatio temporal disaggregation method using posterior predictive BVAR and adjusting procedure at the outsampled location (Tlogo raingage) is very small. So that the spatio temporal disaggregation method using posterior predictive BVAR and adjusting procedure can produce hourly rainfall data which is no different from the hourly observation rainfall data. So as total of 24 hourly prediction rainfall data is same as daily observation data.

The Third Case. Predict or Generate hourly data in the future for insampled and outsampled locations. In this case, the method of spatio temporal disaggregation using the posterior prediction BVAR and adjusting procedure was carried out to predict rainfall data at low time scales (hourly) in the future (January 2008) at the insampled (Sentral and Maesan rainages) and outsampled locations (Tlogo rainage) based on high time scale observation data. Comparison of hourly rainfall data between predictions and observations in January 2008 at the insampled and outsampled locations is presented in Figure 7. Meanwhile the daily rainfall prediction data (a total of 24 hourly prediction data) with daily observation data in the future (January 2008) at the insampled and outsampled locations is presented in the Figure 8.

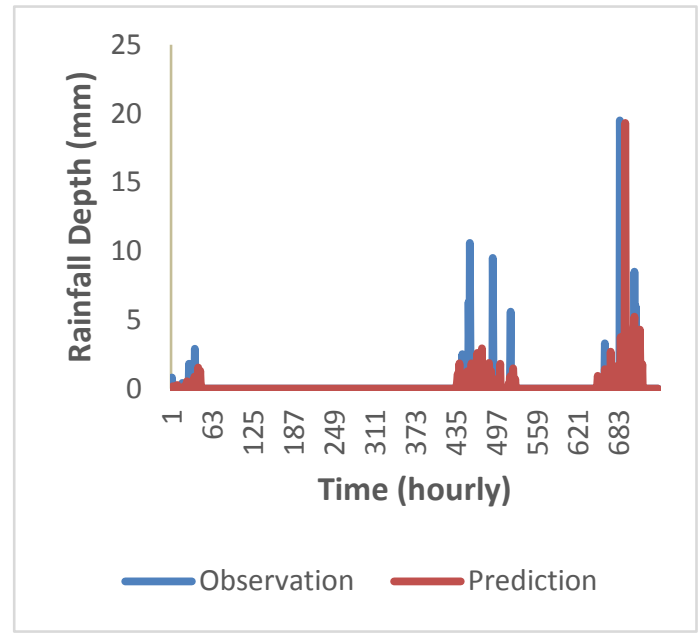

(a) Sentral

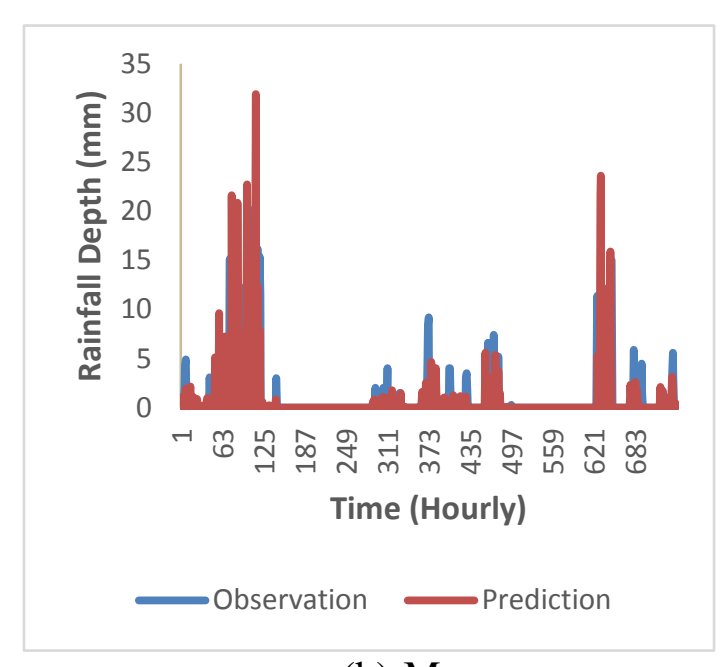

(b) Maesan 


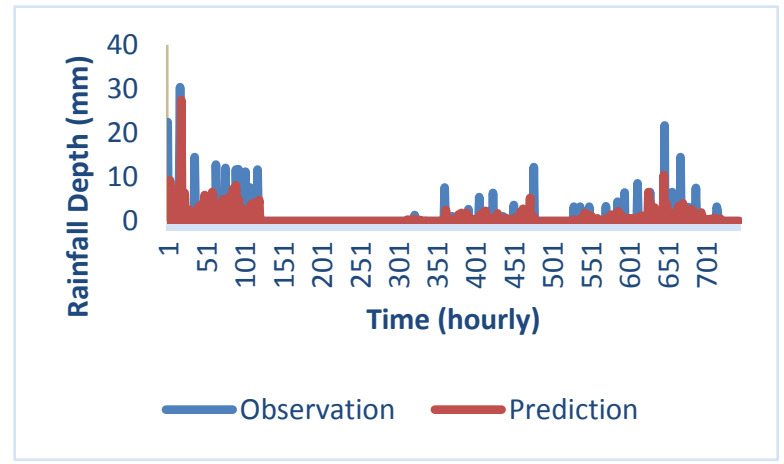

(c) $\mathrm{T} \log \mathrm{O}$

Figure 7. Comparison of hourly rainfall data between predictions and observations in January 2008 at the insampled locations (a) Sentral, (b) Maesan and outsampled locations (c) Tlogo

Based on Figure 7 shows that there are no differences in patterns between hourly predictive and observations rainfall data in the future (january 2008) at the insampled locations (Sentral and Maesan raingages) and outsampled location (Tlogo raingage). This is also supported by the $\mathrm{p}$ value of the test result of 1. $(>\alpha=5 \%)$.

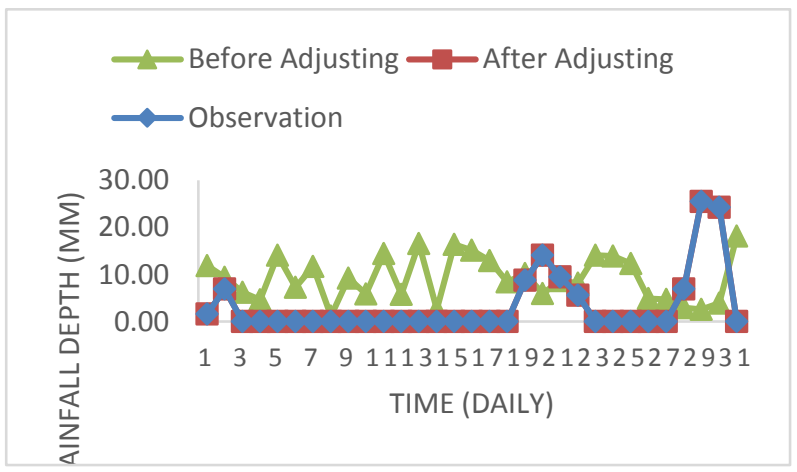

(a) Sentral

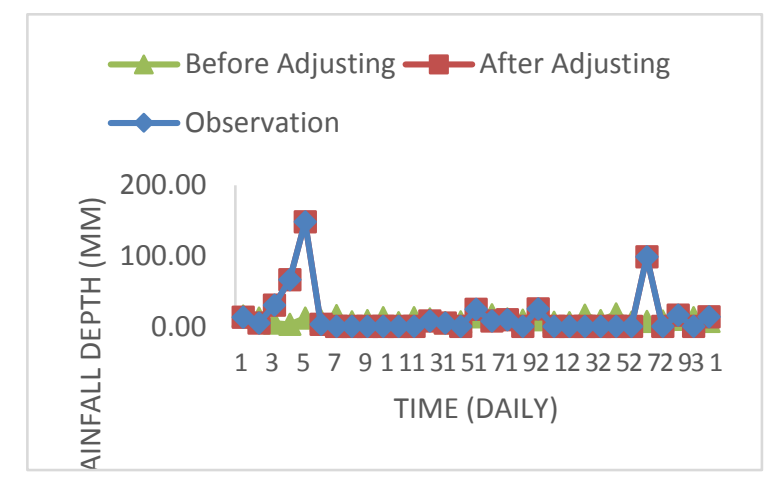

(b) Maesan

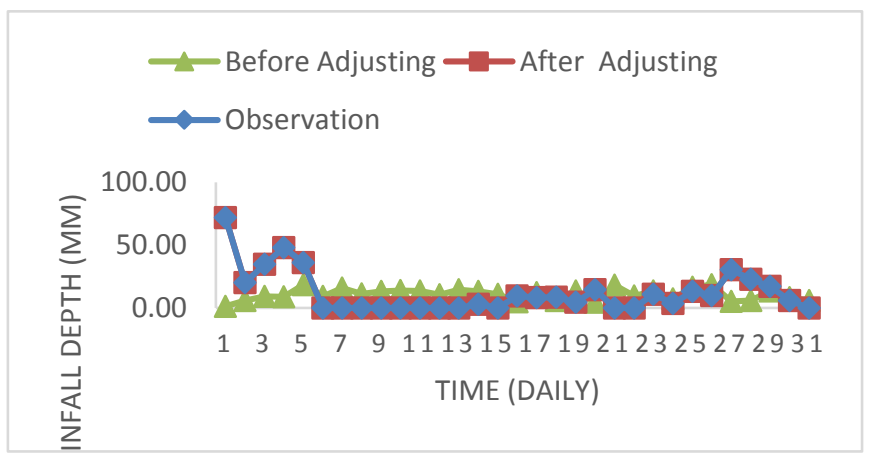

(c) $\mathrm{T} \log \mathrm{O}$

Figure 8. Comparison of daily rainfall data between predictions and observations in January 2008 at the insampled locations (a) Sentral, (b) Maesan and outsampled locations (c) Tlogo 
Based on Figure 8 it is seen that there is no difference in plot between daily rainfall data between posterior predictive BVAR with adjusting procedure and observation compared without adjusting procedure in the future (January 2008) at the insampled locations (Sentral and Maesan) and the outsampled location (Tlogo). Figure 9 shows relationship between daily observation and posterior predictive BVAR with and without adjusting procedure in the future (January 2008) at the insampled locations (Sentral and Maesan) and the outsampled location (Tlogo).

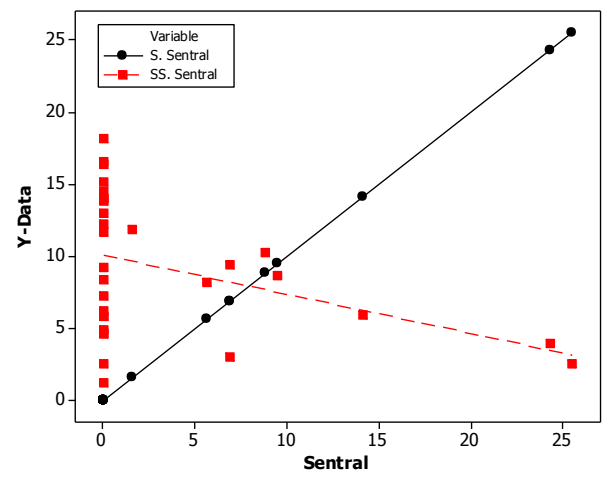

(a) Sentral

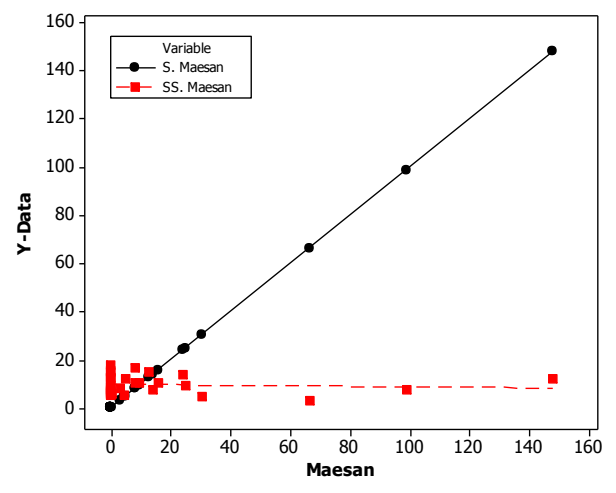

(b)Maesan

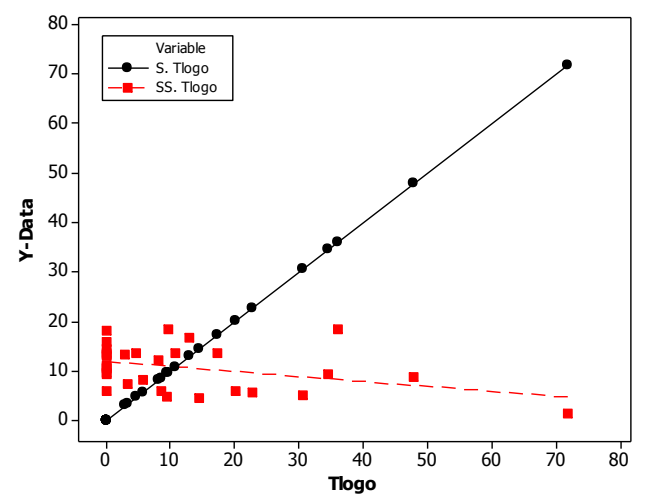

(c) Tlogo

Figure 9. Plot of high time scale data (daily) between Observation vs Posterior Prediction BVAR with adjusting and without adjusting in the future at the insampled locations (a)

Sentral, (b) Maesan and the outsampled location (c) Tlogo raingage

Figure 9 shows the plot line between the daily data between the posterior predictive BVAR and adjusting procedure and daily observations that form an angle of $45^{\circ}\left(\mathrm{R}^{2}=\right.$ $100 \%$ ). This means that the daily data of the posterior predictive predictions of BVAR with adjusting procedure are similar to the daily observational data. Conversely the plot line between the daily data between the posterior predictive BVAR without adjusting procedure and daily observation does not show a linear relationship $\left(\mathrm{R}^{2}=15.1 \%\right.$ for Sentral, $\mathrm{R}^{2}=0.8 \%$ for Maesan, and $\mathrm{R}^{2}=14.1 \%$ for Tlogo). This means that the spatio temporal disaggregation method using posterior predictive BVAR and adjusting procedure is able to produce hourly rainfall data based on daily observation data in the future at the insampled (Sentral and Maesan) and the outsampled locations (Tlogo raingage). 
MAE value of posterior predictive BVAR and adjusting procedure in the future at the insampled (Sentral and Maesan) and the outsampled locations (Tlogo raingage) is shown on Table 2.

\section{Table 2. Comparison of model accuracy in the future at the insampled and the outsampled locations}

\begin{tabular}{|c|c|}
\hline Raingage & MAE \\
\hline Sentral & 0.0005 \\
\hline Maesan & 0.0000 \\
\hline Tlogo & 0.0302 \\
\hline
\end{tabular}

Table 2 shows that the MAE value of the spatio temporal disaggregation method using posterior predictive BVAR and adjusting procedure in the future (January 2008) at the insampled (Sentral and Maesan) and the outsampled location (Tlogo raingage) is very small. So that the spatio temporal disaggregation method using posterior predictive BVAR and adjusting procedure can produce hourly rainfall data which is no different from the hourly observation rainfall data. So as total of 24 hourly prediction rainfall data is same as daily observation data.

\section{Conclusions}

In this paper, We propose a modified method to spatio temporal disaggregation using combination between posterior predictive BVAR and adjusting procedure. Posterior predictive BVAR with an adjusting procedure is able to maintain predictive daily data (obtained from the total per 24 hours of predictive data) with daily data of observation. This method can be used to predict low time scale data (hourly) from high time scale data (daily) at the insampled and outsampled locations. Hourly predictive data obtained from this spatio temporal disaggregation method can be used as an input for simulating runoff rain through hydrographs as early detection of floods.

\section{References}

1. Astutik S., Iriawan,N., Suhartono, dan Sutikno. (2013). Bayesian State-Space Modeling for Spatio-Temporal Rainfall Disaggregation, International Journal of Applied Mathematics and Statistics (IJAMAS), 37 /7 : 26-37.

2. Astutik, S., Sa'adah, U., Adhisuwignjo, S., and Sumara, R., (2017). Pendekatan Distribusi Predictive Posterior Bayesian pada Model Curah Hujan. Prosiding Seminar Nasional SiMantap. Universitas Lambung Mangkurat. Banjarmasin. 
3. Astutik, S., Sa'adah, U., Adhisuwignjo, S., and Sumara, R., (2018). The Daily and Hourly Rainfall Data Modeling using Vector Autoregressive (VAR) with Maximum Likelihood Estimator (MLE) and Bayesian Method. Preprint.

4. Bojilova, E. K. (2004). Disaggregation Modelling of Spring Discharges. International Journal of Speleol, 3(1/4), 65-72.

5. Congdon, P. (2003). Applied Bayesian Modelling, John Wiley \& Sons. England

6. Koutsoyiannis, D., Onof, C., dan Wheater, H. S. (2003). Multivariate Rainfall Disaggregation at a Fine Time Scale. Water Resources Research, 39 (7), 1173.

7. Makhnin, O. V. dan McAllister, D. L. (2009). Stochastic Precipitation Generation Based on a Multivariate Autoregression Model. J. Hydrometeor , 10(6), 13971413.

8. Segond, M. L., Onof, C., dan Wheater, H. S. (2006). Spatial Temporal Disaggregation of Daily Rainfall from a Generalized Linear Model. Journal of Hydrology , 331 (3-4), 674-689.

9. Segond, M.-L., Neokleous, N., Makropoulus, C., Onof, C., dan Maksimovic, C. (2007). Simulation and Spatio-Temporal Disaggregation of Multi-site Rainfall Data for Urban Drainage Application. Hydrological Sciences-Journal , 52(5), 917935. 